$\angle$ Research Square

\title{
Short-Term Outcome and Characteristics of Critical Care for Non-Trauma Patients in the Emergency Department
}

\section{Jessika Stefanie Kreß}

Kliniken Maria Hilf GmbH

Marc Rüppel

Kliniken Maria Hilf GmbH

Hendrik Haake

Kliniken Maria Hilf GmbH

Jürgen vom Dahl

Kliniken Maria Hilf GmbH

Sebastian Bergrath ( $\nabla$ sebastian.bergrath@mariahilf.de)

Kliniken Maria Hilf GmbH https://orcid.org/0000-0001-5297-7655

Original research

Keywords: resuscitation room, critical care, non-trauma patients, emergency department, mortality

Posted Date: June 19th, 2020

DOI: https://doi.org/10.21203/rs.3.rs-36412/v1

License: (c) (i) This work is licensed under a Creative Commons Attribution 4.0 International License. Read Full License 


\section{Abstract}

Background: Emergency medical care for critically ill patients varies between different emergency departments (ED) and health care systems, while resuscitation of trauma patients is always performed within the ED. In many ED critically ill patients are treated and stabilized while in many German ED they are transferred to intensive care units (ICU) without performing of critical care measures in the ED. Against this background we conducted this retrospective analysis of prospectively collected critically ill patients treated with an ED critical care concept in a 754-bed teaching hospital.

Methods: The collective of prospectively collected critically ill patients (October 1st 2018 to March 31st 2019) was analysed after ethical approval. Patient characteristics, performed critical care measures, short-term outcomes and the comparison of admission characteristics between survivors and nonsurvivors were evaluated. Additionally the accordance of ED diagnoses and discharge diagnoses were analysed.

Results: Overall $243 / 19,854$ patients (1.22\%) were treated within the resuscitation room. After exclusion of trauma patients, 193 critically ill patients were included. Overall mortality was $29 \%(n=56), 24$-hour mortality was $13 \%(n=25)$. Patient characteristics (vital signs, blood gas analysis) differed significantly between survivors and non-survivors except for respiratory rate and pain scale. Conducted critical care measures (number \pm standard deviation; e.g. endotracheal intubation, arterial-line): $4.06 \pm 1.73$ (survivors) and $4.70 \pm 2.0$ (non-survivors) $p=0.0453$. The length of ED stay was $148.2 \pm 202.7$ min. Admission diagnoses matched with hospital discharge diagnoses in $73.7 \%$.

Conclusions: Critical care stabilisation of non-trauma patients was feasible in routine care. The observed mortality was high and non-survivors showed significantly more impaired vital parameters and blood gas analysis parameters. Vital parameters together with blood gas analysis enable ED risk stratification of CIP. Although a first diagnostic workup was performed within the ED, admission and discharge diagnoses matched only in $73.7 \%$. However, stabilisation and diagnostic workup of CIP enables optimal allocation to specialized ICUs. Future (randomised) trials have to evaluate of resuscitation room stabilisation for nontrauma patients is beneficial in contrast to direct ICU admission.

Trial registration: The study was registered retrospectively in the Clinical Trials Centre of the RWTH Aachen University (Germany), registration number CTC-A 20-131.

\section{Introduction}

In emergency departments (ED) initial patient care is mostly based on clinical symptoms and vital parameters. Many patients show unspecific symptoms like reduced level of consciousness [1]. More detailed diagnoses are often possible as recently as after lab work and radiology results. Only with these results emergency patients can be allocated to the correct medical specialty. In larger hospitals with different specialty based intensive care units (ICU) a correct allocation of intensive care patients is often only possible after a first diagnostic workup. ICU beds are limited resources and not always available just 
in time, therefore correct allocation is crucial to ensure hospital operability. While in many countries all patients transported via emergency medical service (EMS) are admitted in the ED, in other countries critically ill patients are also admitted directly to ICU. In trauma patients admission via the resuscitation room became standard and led to improved outcomes, but systems of care differ especially in nontrauma patients with a need for immediate critical care measures [2]. In Germany concepts vary also widely between resuscitation room management for CIP and direct ICU admission. In many German EDs critically ill patients are transferred rapidly to the ICU without performing critical care measures in the ED. A direct admission from the emergency medical service to ICU - which is standard in many German hospitals - might lead to wrong patient allocation. Additionally, the correct ICU bed is not always available at this time point. Furthermore, it is well known that a structured interdisciplinary resuscitation room workup is beneficial in major trauma and is one key element that led to mortality reduction [2]. Consecutively, direct admission of trauma patients to ICU is already abandoned since more than two decades. In critically ill non-trauma patients it is unknown if resuscitation room care is beneficial and concepts vary not only from country to country but also from hospital to hospital. Even mortality and severity of non-trauma critically ill patients are not well studied in contrast to multiple scientific evaluations in trauma trials and trauma registers. Against this background we evaluated a critical care emergency room concept for non-trauma patients. Patient characteristics, medical severity, conducted critical care procedures carried out and short-term outcome should be analysed.

\section{Methods}

\section{Study design}

We conducted a single-centre retrospective, observational follow-up study. Data collection and patient inclusion was performed prospectively for quality management purposes in a local resuscitation room registry. To analyse resuscitation room data a questionnaire with checkboxes about the performed procedures was implemented and used for every patient that was judged as critical care patient due to performed critical care measures. The study was carried out from October 1st 2018 until March 31st 2019 (Kliniken Maria Hilf, Mönchengladbach, academic teaching hospital of the University Hospital RWTH Aachen, Germany).

\section{Setting}

The emergency department in our 754-bed academic teaching hospital runs three resuscitation rooms. One of them was mainly used for trauma care and two were mainly used for non-trauma critical care.

Video laryngoscopy (McGrath, Medtronic, Minneapolis, MN, USA and C-MAC, Karl Storz, Tuttlingen, Germany), point of care blood gas analysis including haemoglobin, electrolytes, glucose and lactate, a mobile sonography unit (Xario 100G, Canon Medical Systems GmbH, Neuss, Germany) and a mechanical chest compression device (LUCAS 2, Jolife AB, Lund, Sweden) were available in a central storage of the ED. 


\section{Inclusion criteria}

We included all patients that were initially classified as non-trauma critically ill patients that showed no stable vital parameters and/or with a need for critical care measures. Exclusion criteria were patients with a pre-known palliative status. Patients with signs of acute stroke and acute coronary syndromes with stable vital parameters and no need for critical care procedures were excluded, even when they were locally treated within one of the three resuscitation rooms.

\section{Outcome parameters}

The following outcomes were evaluated: performed critical care measures within the ED, ED diagnoses and discharge diagnoses and as well as their accordance, length of stay in the resuscitation room, 24hour mortality and in-hospital mortality. Furthermore it should be analysed if performed measures and initial patient characteristics differed between survivors and non-survivors to allow future risk stratification.

\section{Data sources}

A patient data management and electronic health record system (iMedOne, Deutsche Telekom Healthcare and Security Solutions $\mathrm{GmbH}$, Bonn, Germany) served as the main data source. For quality management purposes a prospective local registry of critical care resuscitation room management (Excel, Microsoft Corporation, Redmond, WA, USA) using pseudonymized patient data complemented the electronic health records. Pseudonymized data of the aforementioned questionnaire was transferred into this secured and user-restricted database and was amended by secondarily pseudonymized patient data of the electronic health records.

\section{Ethics committee approval and data privacy}

Due to the process that only routine data was collected and all data analyses were performed in a pseudonymized way the ethics committee (University hospital Aachen, Germany) waived personal consent by patients or ED personnel (EK051/20). The study was registered in the Clinical Trials Centre of the RWTH Aachen University (registration number CTC-A 20-131) and meets the criteria of the STROBE statement [3].

\section{Statistical analyses}

Performed procedures, short-term outcome and diagnoses were analysed with descriptive data. The comparison of admission characteristics of survivors and non-survivors were performed using the MannWhitney-U test. Due to exploratory character of the study $\mathrm{p}$-values $<0.05$ were considered to be significant. All statistical analyses were carried out with Prism 8.4.2 GraphPad Software, San Diego, CA, USA.

\section{Results}

\section{Patient characteristics}


Overall 243 of 19,854 (1.22\%) ED patients were treated as resuscitation room patients from October 1st 2018 to March 31st 2019. Patients with traumatic injuries were excluded secondarily (Fig. 1).

Demographics and patient characteristics of the 193 included critically ill patients are summarized in Table 1.

Table 1

Patient demographics and characteristics

\begin{tabular}{|c|c|}
\hline $\begin{array}{l}\text { Parameter at admission } \\
\text { (number of patient with data available) }\end{array}$ & $\begin{array}{l}\text { Non-trauma critical care ED patients } \\
\text { mean } \pm \text { SD (range) }\end{array}$ \\
\hline age $(n=193)$ & $65.8 \pm 16.0(17-94)$ \\
\hline $\operatorname{sex}(n=193)$ & female $87\{45 \%\}$ \\
\hline respiratory rate (per $\mathrm{min}) \mathrm{n}=105$ & $22.35 / \min \pm 8.46 / \min (8-51)$ \\
\hline $\mathrm{SpO}_{2}(\%) \mathrm{n}=112$ & $91.38 \pm 9.67(51-100)$ \\
\hline heart rate $(\mathrm{bpm}) \mathrm{n}=117$ & $94.66 \pm 32.67(0-171)$ \\
\hline systolic blood pressure $(\mathrm{mmHg}) \mathrm{n}=111$ & $130.97 \pm 45.14(0-256)$ \\
\hline Glasgow Coma Scale $n=157$ & $11.41 \pm 4.19(3-15)$ \\
\hline pain scale $(0-10), n=25$ & $1.32 \pm 2.38(0-10)$ \\
\hline \multicolumn{2}{|c|}{ blood gas analysis (arterial/capillary/venous) } \\
\hline hemoglobin $(\mathrm{g} / \mathrm{dL}) \mathrm{n}=180$ & $12.53 \pm 2.84(3.6-21)$ \\
\hline $\mathrm{pH}(\mathrm{n}=164)$ & $7.29 \pm 0.160(6.59-7.58)$ \\
\hline base excess $(n=160)$ & $-2.56 \pm 8.62(-28.3-37.2)$ \\
\hline Lactate $(\mathrm{mmol} / \mathrm{l})(\mathrm{n}=164)$ & $3.48 \pm 3.97(0.3-21)$ \\
\hline $\begin{array}{l}\mathrm{pO}_{2}(\mathrm{mmHg}) \\
\text { arterial }+ \text { capillary } \mathrm{n}=133\end{array}$ & $109.31 \pm 68.97(26.7-402)$ \\
\hline $\begin{array}{l}\mathrm{pCO}_{2}(\mathrm{mmHg}) \\
\text { arterial + venous. } \mathrm{n}=166\end{array}$ & $52.06 \pm 23.56(18.4-165)$ \\
\hline
\end{tabular}

\section{Resuscitation and critical care measures}


In Table 2 the conducted critical measures are displayed. A mean of 4.24 (SD 1.82, range 1-9) critical care measures were performed in each patient. Critically ill patients $(n=186$ with available data) had a length of stay of $148.2 \mathrm{~min}$ (SD $202.7 \mathrm{~min}$ ) in the resuscitation room, including the time period of transports to radiology.

Table 2

Critical care measures in the resuscitation room

\begin{tabular}{|lll|}
\hline Procedure/measure & number & percentage \\
\hline primary and secondary survey & 183 & $94.8 \%$ \\
\hline fluid resuscitation & 104 & $53.9 \%$ \\
\hline sedation & 99 & $51.3 \%$ \\
\hline arterial line & 78 & $40.4 \%$ \\
\hline transport with medical doctor to CT/MRI & 65 & $33.7 \%$ \\
\hline non-invasive ventilation & 60 & $31.1 \%$ \\
\hline endotracheal intubation and mechanical ventilation & 56 & $29.0 \%$ \\
\hline catecholamine administration & 48 & $24.9 \%$ \\
\hline abdominal sonography & 27 & $14.0 \%$ \\
\hline Echocardiography & 26 & $13.5 \%$ \\
\hline thoracic sonography & 20 & $10.4 \%$ \\
\hline cardiopulmonary resuscitation & 19 & $9.8 \%$ \\
\hline electric cardioversion & 11 & $5.7 \%$ \\
\hline central venous line & 8 & $4.2 \%$ \\
\hline intraosseous access & 6 & $3.1 \%$ \\
\hline chest tube & 4 & $2.1 \%$ \\
\hline bronchoscopy & 2 & $1.0 \%$ \\
\hline CT, computed tomography; MRI, magnetic resonance imaging & \\
\hline
\end{tabular}

\section{Outcomes}


Twenty-four-hour mortality was $13 \%(n=25)$. All of these patients died within the resuscitation room or ED and were not admitted to the ICU. From this subgroup $n=11$ were already admitted under on-going cardiopulmonary resuscitation by the EMS at ED handover. Overall hospital mortality was $29 \%(n=56)$.

\section{Admission and discharge diagnoses}

Table 3 sets the ED diagnosis against the hospital discharge diagnosis. Respiratory insufficiency, reduced level of consciousness and sepsis were the main ED admission diagnoses. In 73.7\% $(n=146)$ ED diagnoses and discharge diagnosis matched after clinical review by the authors, a disconcordance was detected in $26.3 \%$ consecutively.

\section{Comparison of survivors vs. non-survivors}

Patient characteristics at admission differed significantly between survivors and non-survivors except for respiratory rate and pain scale. (Table 4). Between survivors and non-survivors the amount of conducted critical care procedures in the ED differed also: 4.06 (SD 1.73) vs. 4.70 (SD 2.0), $p=0.0453$. 
Table 3

Correlation between symptoms in the Emergency room and discharge diagnosis

\begin{tabular}{|c|c|c|}
\hline symptoms at admission & $\begin{array}{l}\text { diagnosis at hospital } \\
\text { discharge }\end{array}$ & $\begin{array}{l}\text { Matching of symptoms with } \\
\text { discharge diagnosis (number of } \\
\text { patients (\%)) }\end{array}$ \\
\hline dyspnea & pneumonia/COPD & $67(85.9 \%)$ \\
\hline$n=78$ & $\begin{array}{l}\text { Heart failure / pulmonary } \\
\text { edema }\end{array}$ & \\
\hline $\begin{array}{l}\text { sepsis (hypotonia, fever, } \\
\text { shock) } n=17\end{array}$ & sepsis & $12(70.5 \%)$ \\
\hline $\begin{array}{l}\text { unconsciousness } \\
n=43\end{array}$ & $\begin{array}{l}\text { drugs intoxication / } \\
\text { intracranial bleeding / } \\
\text { stroke/ seizure }\end{array}$ & $32(74.4 \%)$ \\
\hline $\begin{array}{l}\text { other neurological } \\
\text { symptoms (sudden } \\
\text { numbness or paresis) }\end{array}$ & stroke & $3(50 \%)$ \\
\hline$n=6$ & & \\
\hline $\begin{array}{l}\text { Chest Pain } \\
n=4\end{array}$ & myocardial infarction & $4(100 \%)$ \\
\hline $\begin{array}{l}\text { Tachycardia / Palpitations } \\
n=6\end{array}$ & $\begin{array}{l}\text { atrial fibrillation/AVNRT/ } \\
\text { narrow / wide-complex } \\
\text { tachycardia }\end{array}$ & $6(100 \%)$ \\
\hline $\begin{array}{l}\text { Bradycardia } \\
n=2\end{array}$ & $\begin{array}{l}\text { AV-Block / sick sinus } \\
\text { syndrome }\end{array}$ & $2(100 \%)$ \\
\hline $\begin{array}{l}\text { Abdominal complaints } \\
n=2\end{array}$ & ileus & $1(50 \%)$ \\
\hline $\begin{array}{l}\text { Hemodynamic relevant } \\
\text { bleeding } \\
n=12\end{array}$ & gastrointestinal bleeding & $7(58.3 \%)$ \\
\hline $\begin{array}{l}\text { Cardiopulmonary } \\
\text { Resuscitation } \\
n=11\end{array}$ & $\begin{array}{l}\text { successful resuscitation/ } \\
\text { death during resuscitation }\end{array}$ & $11(100 \%)$ \\
\hline $\begin{array}{l}\text { Miscellaneous } \\
\mathrm{n}=12\end{array}$ & $\begin{array}{l}\text { miscellaneous (pulmonary } \\
\text { embolism, aortic dissection) }\end{array}$ & $8(66.7 \%)$ \\
\hline
\end{tabular}

COPD, chronic obstructive pulmonary disease; AVNRT, AV-node reentry tachycardia 


\begin{tabular}{|c|c|c|}
\hline symptoms at admission & $\begin{array}{l}\text { diagnosis at hospital } \\
\text { discharge }\end{array}$ & $\begin{array}{l}\text { Matching of symptoms with } \\
\text { discharge diagnosis (number of } \\
\text { patients (\%)) }\end{array}$ \\
\hline $\begin{array}{l}\text { Overall } \\
n=153\end{array}$ & & $\begin{array}{l}73.7 \% \text { concordance of admission } \\
\text { and discharge diagnosis }\end{array}$ \\
\hline
\end{tabular}


Table 4

Comparison of survivors and non-survivors

\begin{tabular}{|c|c|c|c|}
\hline $\begin{array}{l}\text { characteristics / parameter at } \\
\text { admission }\end{array}$ & $\begin{array}{l}\text { survivors ( } n=137) \\
\text { mean } \pm \text { SD (Range) }\end{array}$ & $\begin{array}{l}\text { non-survivors }(n=56) \\
\text { mean } \pm \text { SD (Range) }\end{array}$ & $p$ value \\
\hline age & $\begin{array}{l}62.4 \pm 16.1(17- \\
92 \text { years })\end{array}$ & $74.4 \pm 13$ (19-94 years) & $\begin{array}{l}\mathrm{p}< \\
0.0001\end{array}$ \\
\hline sex & female $n=104\{53.9 \%\}$ & male $n=89\{46.1 \%\}$ & \\
\hline respiratory rate & $22.46 \pm 8.37(8-48 / \mathrm{min})$ & $\begin{array}{l}22.06 \pm 8.97(10- \\
51 / \mathrm{min})\end{array}$ & $\begin{array}{l}p= \\
0.6817\end{array}$ \\
\hline (per min) & $n=104$ & $\mathrm{n}=35$ & \\
\hline \multirow[t]{2}{*}{$\mathrm{SpO}_{2}(\%)$} & $92.28 \pm 9.72(51-100 \%)$ & $86.45 \pm 9.23(70-100 \%)$ & \multirow{2}{*}{$\begin{array}{l}p= \\
0.0092\end{array}$} \\
\hline & $\mathrm{n}=109$ & $\mathrm{n}=35$ & \\
\hline \multirow[t]{2}{*}{ heart rate (bpm) } & $\begin{array}{l}99.53 \pm 26.52(30-171 / \\
\min )\end{array}$ & $\begin{array}{l}80.105 \pm 44.14(0- \\
160 / \mathrm{min})\end{array}$ & \multirow[t]{2}{*}{$\begin{array}{l}p= \\
0.0157\end{array}$} \\
\hline & $\mathrm{n}=111$ & $n=37$ & \\
\hline \multirow[t]{2}{*}{ systolic blood pressure (mmHg) } & $\begin{array}{l}140.9 \pm 33.51(76- \\
253 \mathrm{mmHg})\end{array}$ & $\begin{array}{l}104.07 \pm 61.71(0- \\
256 \mathrm{mmHg})\end{array}$ & \multirow[t]{2}{*}{$\begin{array}{l}p< \\
0.0001\end{array}$} \\
\hline & $\mathrm{n}=106$ & $\mathrm{n}=40$ & \\
\hline \multirow[t]{3}{*}{ Glasgow coma scale } & $12.2 \pm 3,78(3-15)$ & $9.33 \pm 4.579(3-15)$ & \multirow{3}{*}{$\begin{array}{l}p< \\
0.0001\end{array}$} \\
\hline & Median:15 IQR: 5 & Median: 10 IQR: 9.5 & \\
\hline & $\mathrm{n}=127$ & $\mathrm{n}=48$ & \\
\hline \multirow[t]{3}{*}{ pain scale $(0-10)$} & $1.49 \pm 2.46(0-8)$ & $0.93 \pm 2.2(0-8)$ & \multirow{3}{*}{$\begin{array}{l}\square p= \\
0.4254\end{array}$} \\
\hline & Median 0, IQR 2.75 & Median 0, IQR 0 & \\
\hline & $\mathrm{n}=56$ & $\mathrm{n}=15$ & \\
\hline \multirow[t]{2}{*}{ hemoglobin (g/dL) } & $\begin{array}{l}12.77 \pm 2.82(3.6- \\
21.0 \mathrm{~g} / \mathrm{dL})\end{array}$ & $\begin{array}{l}11.85 \pm 2.84(6.4- \\
17.7 \mathrm{~g} / \mathrm{dL})\end{array}$ & \multirow[t]{2}{*}{$\begin{array}{l}\square p= \\
0.0273\end{array}$} \\
\hline & $n=137$ & $\mathrm{n}=49$ & \\
\hline \multirow[t]{2}{*}{$\mathrm{pH}$} & $7.32 \pm 0.12(6.94-7.58)$ & $7.23 \pm 0.21(6.59-7.52)$ & \multirow[t]{2}{*}{$\varangle 0.0150$} \\
\hline & $n=125$ & $n=53$ & \\
\hline \multirow[t]{2}{*}{ base excess } & $-1.38 \pm 7.55(-21.9-37.2)$ & $\begin{array}{l}-5.34 \pm 10.34(-28.3- \\
17.2)\end{array}$ & \multirow[t]{2}{*}{0.0245} \\
\hline & $n=123$ & $n=53$ & \\
\hline
\end{tabular}




\begin{tabular}{|llll|}
\hline $\begin{array}{l}\text { characteristics / parameter at } \\
\text { admission }\end{array}$ & $\begin{array}{l}\text { survivors }(\mathrm{n}=137) \\
\text { mean } \pm \text { SD (Range) }\end{array}$ & $\begin{array}{l}\text { non-survivors }(\mathrm{n}=56) \\
\text { mean } \pm \text { SD (Range) }\end{array}$ & $p$ value \\
\hline lactate $(\mathrm{mmol} / \mathrm{l})$ & $2.73 \pm 2.85(0.3$ bis 21) & $5.27 \pm 5,49(0.5-20)$ & $p=0.0036$ \\
& $\mathrm{n}=125$ & $\mathrm{n}=53$ & \\
\hline
\end{tabular}

$\mathrm{SD}$, standard deviation; $\mathrm{SpO}_{2}$, pulseoxymetry

\section{Discussion}

Treatment of respiratory failure, airway management, invasive monitoring and circulatory support were the main critical care measures carried out for critically ill patients in the resuscitation room. Some patients turned out to have traumatic injuries and some of these injuries were missed out in the prehospital phase by EMS. Therefore an interdisciplinary resuscitation room concept for all patients with impaired vital parameters with fast primary survey, (invasive) stabilization, early bedside sonography and computed tomography is probably beneficial compared to primary allocation and admission of critically ill patients to specialty based ICUs (e.g. neurological ICU), only based on the main clinical symptom. A relevant amount of patients - especially the non-survivors - showed a reduced level of consciousness ad ED admission as the leading symptom but only a few patients turned out to have neurological diagnoses as the main discharge diagnosis (Tables 1,3 and 4 ).

Our study enables an overview about a mixed, non-limited real-life patient collective in a 754-bed academic teaching hospital, serving for four districts. Most patients showed a reduced level of consciousness, respiratory problems, metabolic or respiratory acidosis and elevated serum lactate while other vital parameters were often only mildly impaired (Table 1 ). The rate of critically ill patients, performed interventions (Table 2) and leading clinical problems (Tables 1, 3 and 4) were comparable to the non-trauma resuscitation room collective described by Bernhard et al at a German university hospital [1].

The amount and type of conducted critical care measures demonstrate that these techniques are crucial skills for interdisciplinary high-volume ED. Especially airway management, non-invasive and invasive ventilation as well as circulatory support are skills that are necessary within the first minutes after patient arrival. Invasive ventilation after rapid sequence induction in the ED was necessary in $29 \%$ of the analysed patients. This fraction is comparable to another collective in a German university hospital [4]. Therefore structured concepts are necessary to enable a guideline-based and rapid medical treatment. For trauma patients certified concepts with courses and certification (e.g. Advanced trauma life support $\circledast$ ) are current standard in every trauma centre, while for non-trauma patients medical and organisational settings differ widely [2,5-7]. In trauma a structured concept and guideline adherence can lead to significant reduction of mortality [8]. The mortality in our collective was much higher compared to major trauma patients in the German Trauma Registry but especially mean age differs between the trauma registry patients and our collective [9]. Overall, airway management in the ED is a current field of clinical 
research although outcome data is mostly not available $[4,10,11]$. A mean ED treatment phase of 148.2 min in our collective points out that this concept led to relevant resource consumption. This must be taken into account when implementing such a strategy. The length of stay in the ED was longer than described by Bernhard et al, but we did not differentiate between the first phase in the resuscitation room and the second phase of transports to computed tomography and treatment time until an ICU-bed was available [1]. Unfortunately we did not document the exact use of human resources regarding consultant, resident and nurse deployment, which is one of the major limitations in our study. Overall, data about resuscitation room management of critically ill patients collectives is rare and therefore it remains unclear if an invasive, rapid approach is generally beneficial compared to less invasive ED care and rapid transfer to ICU. However, rapid critical care treatment in the ED is probably beneficial for patients in septic shock. Very early continuous infusion of norepinephrine seems to be beneficial in septic shock and leads to shortened ICU stay and earlier restoration of circulation [12-14]. If continuous norepinephrine infusion is restricted to ICU settings, delays in shock therapy are probably inevitable. Severe pneumonia with endorgan dysfunction and sepsis of other origin also accounted for a relevant number in our collective (Table 3). Invasive measurement of arterial pressure seems to be more accurate in septic shock compared to oscillometric standard measurements [15]. Our approach of frequent placement of arterial lines seems to be more accurate and therefore probably beneficial in correct clinical evaluation and risk stratification. If fluid and vasopressor therapy is delayed due to non-correct oscillometric values, this might affect patient outcome negatively.

Non-trauma patients admitted to the resuscitation room had a high 24-hour and in-hospital mortality which was comparable to another collective described in a German university hospital [1]. All patients that were handed over in the ED under on-going cardiopulmonary resuscitation died in the resuscitation room after airway management and exclusion of reversible causes of cardiac arrest. Overall, the rate of survival in patients transported by EMS under cardiopulmonary resuscitation is low, which is supported by current literature, but outcome data differs widely due to different study settings and criteria [16-18]. If patients with refractory cardiac arrest are transported early and with high quality CPR this might improves outcome [19]. One reason for $100 \%$ fatal outcome in our subgroup was, that patients qualified for venoarterial extracorporal life support (V-A-ECLS) under cardiopulmonary resuscitation bypassed the ED and were directly transferred to our cardiologic ICU via EMS. Patients under on-going CPR were selected via telephonic triage to either resuscitation room or V-A-ECLS in the ICU. In some ED ECLS is already implemented and this resuscitation technique is not restricted to ICU [16]. In the last decade survival of selected patients receiving ECLS improved over time [20].

Admission diagnosis in the resuscitation room matched with discharge diagnosis in $74 \%$ of the patients. In non-pneumonic sepsis higher rates of mismatch between admission diagnosis and discharge diagnosis were observed, compared to other admission diagnoses and pneumogenic sepsis. Atmna et al. reported a discordant diagnosis in patients diagnosed with pneumonia in the ED in 29\% of the cases [21]. However, it remains unclear which factors led to discordant diagnosis in our setting. In supposed gastrointestinal bleedings the rate of discordant diagnosis between ED and ward was $50 \%$. The main 
reason for this observation was probably the time point of documentation. The ED diagnosis was documented prior to transport for esophagogastroscopy.

Non-survivors showed a significant higher rate of conducted critical care measures which is explainable due to more impaired vital functions. Significant baseline differences in vital parameters and blood gas analysis were detected in comparison between survivors vs. non-survivors, except for respiratory rate and pain scale. However, respiratory rate showed a mean of $22 / \mathrm{min}$ in both groups, which is a nonphysiological value. Risk stratification of ED patients during triage and initial assessment is crucial for allocation of patients and resources. Several scores were developed and compared to differentiate critical from non-critical patients [22-24]. All patients included in this study were classified as critically ill patients initially. Within this group - representing $1.22 \%$ of all ED patients - the amount of GCS reduction, acidosis and elevation of lactate were highly significantly associated with fatal outcome. Impaired vigilance and lactate elevation are associated with fatal outcome in ED patients with severe sepsis [25]. Despite several scores to detect patients at risk, failure of vital sign normalisation is more strongly associated with mortality than single measures [23]. Therefore these parameters are useful in risk stratification within the group of already detected critically ill patients. The clinical value of point of care lactate measurement is also shown by Kramer et al, but after exclusion of patients receiving cardiopulmonary resuscitation at ED arrival, initial lactate did not differ between survivors and nonsurvivors [26].

Although it was not purpose of our study often bridging time was observed until ICU admission was possible. It can be assumed that without invasive ED management, the patients would have received some necessary therapy later. Future (randomised) studies have to compare direct ICU admission via EMS versus initial resuscitation room management regarding patient outcome.

\section{Limitations}

Although data was collected prospectively for quality management and clinical review, our study was a retrospective study and data analysis with all its limitations. We used our special resuscitation room questionnaires to include the patients. Therefore we might have missed some patients that were treated invasively due to forgotten questionnaires. We could not differentiate between patients that were already assessed as critical by EMS via physician-to-physician phone communication and patients that turned out to be critical after arrival and no procedures like rapid sequence induction were prepared, because the content of the prehospital phone call was not documented in the health records.

\section{Conclusions}

Our mixed real life clinical collective shows that resuscitation room management for critically ill patients is a complex procedure with a high necessity of invasive procedures. Overall mortality of critically ill patients was high. Beside vital parameters blood gas analysis and lactate allows early risk stratification for fatal outcome. To ensure structured care for these patients at risk we determined three different team 
compositions for the following groups of non-trauma resuscitation room patients as a consequence of our findings: basic team for patients at risk with stable vital parameters; expanded team for patients with unstable vital functions; cardiac arrest receiving team. Future (randomised) studies have to answer if a structured resuscitation room management is beneficial for critically ill patients in contrast to direct ICU admission.

\section{Abbreviations}

CIP: critically ill patients; ECLS: extracorporal life support; ED: emergency department; EMS: emergency medical service; GCS: Glasgow coma scale; ICU: intensive care unit; V-A-ECLS: veno-arterial extracorporal life support

\section{Declarations}

\section{Acknowledgements}

Not applicable

\section{Funding}

The study was performed and funded solely by departmental resources.

\section{Availability of data and materials}

The datasets used and/or analysed during the current study are available from the corresponding author on reasonable request.

\section{Authors' contributions}

JSK and SB designed the study and collected data. Ethics approval was obtained by JSK and SB. SB performed statistical analysis of data, JSK and SB wrote the manuscript draft. Tables and Figures were designed by JK. MR, $\mathrm{HH}$ and JvD helped with the study design and the interpretation of data. MR, $\mathrm{HH}$ and JvD authors critically revised the manuscript. All authors read and approved the final version of the manuscript.

\section{Ethics approval and consent to participate}

The study was approved by the ethics committee of the University Hospital Aachen, RWTH Aachen, Germany, EK 051/20. 


\section{Competing interests}

The authors declare that they have no competing interests.

\section{Ethics committee}

University Hospital RWTH Aachen, Germany, registration number EK 051/20

\section{Funding and Conflict of Interest}

The authors report no specific funding in relation to this research. There are no competing interests.

\section{References}

1. Bernhard M, Döll S, Hartwig T, Ramshorn-Zimmer A, Yahiaoui-Doktor M, Weidhase L, et al. Resuscitation room management of critically ill nontraumatic patients in a German emergency department (OBSERvE-study). Eur J Emerg Med. 2018;25:e9.

2. Thelen S, Michael M, Ashmawy H, Knoefel WT, Picker O, Windolf J, et al. Schockraummanagement bei traumatologischen Patienten. Anaesthesist. 2019;68:49-66.

3. E von E, Dg A, M E, Sj P, Pc G, Jp V. The Strengthening the Reporting of Observational Studies in Epidemiology (STROBE) Statement: Guidelines for Reporting Observational Studies [Internet]. Int. J. Surg. Lond. Engl. 2014 [cited 2020 Jun 11]. Available from:

https://pubmed.ncbi.nIm.nih.gov/25046131/?from_term=STROBE+statement\&from_pos=1

4. Bernhard M, Bax SN, Hartwig T, Yahiaoui-Doktor M, Petros S, Bercker S, et al. Airway Management in the Emergency Department (The OcEAN-Study) - a prospective single centre observational cohort study. Scand J Trauma Resusc Emerg Med. 2019;27:20.

5. Navarro S, Montmany S, Rebasa P, Colilles C, Pallisera A. Impact of ATLS training on preventable and potentially preventable deaths. World J Surg. 2014;38:2273-8.

6. Galvagno SM, Nahmias JT, Young DA. Advanced Trauma Life Support® Update 2019: Management and Applications for Adults and Special Populations. Anesthesiol Clin. 2019;37:13-32.

7. Hilbert-Carius $\mathrm{P}$, Wurmb T, Lier H, Fischer M, Helm M, Lott C, et al. [Care for severely injured persons: Update of the 2016 S3 guideline for the treatment of polytrauma and the severely injured]. Anaesthesist. 2017;66:195-206.

8. Schoeneberg C, Schilling M, Burggraf M, Fochtmann U, Lendemans S. Reduction in mortality in severely injured patients following the introduction of the "Treatment of patients with severe and multiple injuries" guideline of the German society of trauma surgery--a retrospective analysis of a level 1 trauma center (2010-2012). Injury. 2014;45:635-8. 
9. Ali Ali B, Lefering R, Fortun Moral M, Belzunegui Otano T. Epidemiological comparison between the Navarra Major Trauma Registry and the German Trauma Registry (TR-DGU®). Scand J Trauma Resusc Emerg Med. 2017;25:107.

10. Jiang J, Kang N, Li B, Wu A-S, Xue F-S. Comparison of adverse events between video and direct laryngoscopes for tracheal intubations in emergency department and ICU patients-a systematic review and meta-analysis. Scand J Trauma Resusc Emerg Med. 2020;28:10.

11. Sulser S, Ubmann D, Schlaepfer M, Brueesch M, Goliasch G, Seifert B, et al. C-MAC videolaryngoscope compared with direct laryngoscopy for rapid sequence intubation in an emergency department: $\mathrm{A}$ randomised clinical trial. Eur J Anaesthesiol. 2016;33:943-8.

12. Ospina-Tascón GA, Hernandez G, Alvarez I, Calderón-Tapia LE, Manzano-Nunez R, Sánchez-Ortiz Al, et al. Effects of very early start of norepinephrine in patients with septic shock: a propensity scorebased analysis. Crit Care Lond Engl. 2020;24:52.

13. Keijzers G, Macdonald SP, Udy AA, Arendts G, Bailey M, Bellomo R, et al. The Australasian Resuscitation In Sepsis Evaluation: Fluids or vasopressors in emergency department sepsis (ARISE FLUIDS), a multi-centre observational study describing current practice in Australia and New Zealand. Emerg Med Australas EMA. 2020;

14. Permpikul C, Tongyoo S, Viarasilpa T, Trainarongsakul T, Chakorn T, Udompanturak S. Early Use of Norepinephrine in Septic Shock Resuscitation (CENSER). A Randomized Trial. Am J Respir Crit Care Med. 2019;199:1097-105.

15. Meidert AS, Dolch ME, Mühlbauer K, Zwissler B, Klein M, Briegel J, et al. Oscillometric versus invasive blood pressure measurement in patients with shock: a prospective observational study in the emergency department. J Clin Monit Comput. 2020;

16. Swol J, Belohlávek J, Brodie D, Bellezzo J, Weingart SD, Shinar Z, et al. Extracorporeal life support in the emergency department: A narrative review for the emergency physician. Resuscitation. 2018;133:108-17.

17. Goto Y, Funada A, Maeda T, Okada H, Goto Y. Field termination-of-resuscitation rule for refractory outof-hospital cardiac arrests in Japan. J Cardiol. 2019;73:240-6.

18. Gregers E, Kjærgaard J, Lippert F, Thomsen JH, Køber L, Wanscher M, et al. Refractory out-of-hospital cardiac arrest with ongoing cardiopulmonary resuscitation at hospital arrival - survival and neurological outcome without extracorporeal cardiopulmonary resuscitation. Crit Care Lond Engl. 2018;22:242.

19. Adler C, Paul C, Michels G, Pfister R, Sabashnikov A, Hinkelbein J, et al. One year experience with fast track algorithm in patients with refractory out-of-hospital cardiac arrest. Resuscitation. 2019;144:157-65.

20. Hadaya J, Dobaria V, Aguayo E, Kwon OJ, Sanaiha Y, Hyunh A, et al. National Trends in Utilization and Outcomes of Extracorporeal Support for In- and Out-of-Hospital Cardiac Arrest. Resuscitation. 2020; 
21. Atamna A, Shiber S, Yassin M, Drescher MJ, Bishara J. The accuracy of a diagnosis of pneumonia in the emergency department. Int J Infect Dis IJID Off Publ Int Soc Infect Dis. 2019;89:62-5.

22. Viglino D, L'her E, Maltais F, Maignan M, Lellouche F. Evaluation of a new respiratory monitoring tool "Early Warning Score02" for patients admitted at the emergency department with dyspnea. Resuscitation. 2020;148:59-65.

23. Levin N, Horton D, Sanford M, Horne B, Saseendran M, Graves K, et al. Failure of vital sign normalization is more strongly associated than single measures with mortality and outcomes. Am J Emerg Med. 2019;

24. Brink A, Alsma J, Verdonschot RJCG, Rood PPM, Zietse R, Lingsma HF, et al. Predicting mortality in patients with suspected sepsis at the Emergency Department; A retrospective cohort study comparing qSOFA, SIRS and National Early Warning Score. PloS One. 2019;14:e0211133.

25. Carbó M, Fresco L, Osorio G, Monclús E, Ortega M. Predictors of mortality in emergency department patients with sepsis scored 2 or 3 on the Quick Sequential Organ Failure Assessment scale. Emerg Rev Soc Espanola Med Emerg. 2020;32:169-76.

26. Kramer A, Urban N, Döll S, Hartwig T, Yahiaoui-Doktor M, Burkhardt R, et al. Early Lactate Dynamics in Critically III Non-Traumatic Patients in a Resuscitation Room of a German Emergency Department (OBSERvE-Lactate-Study). J Emerg Med. 2019;56:135-44.

\section{Figures}




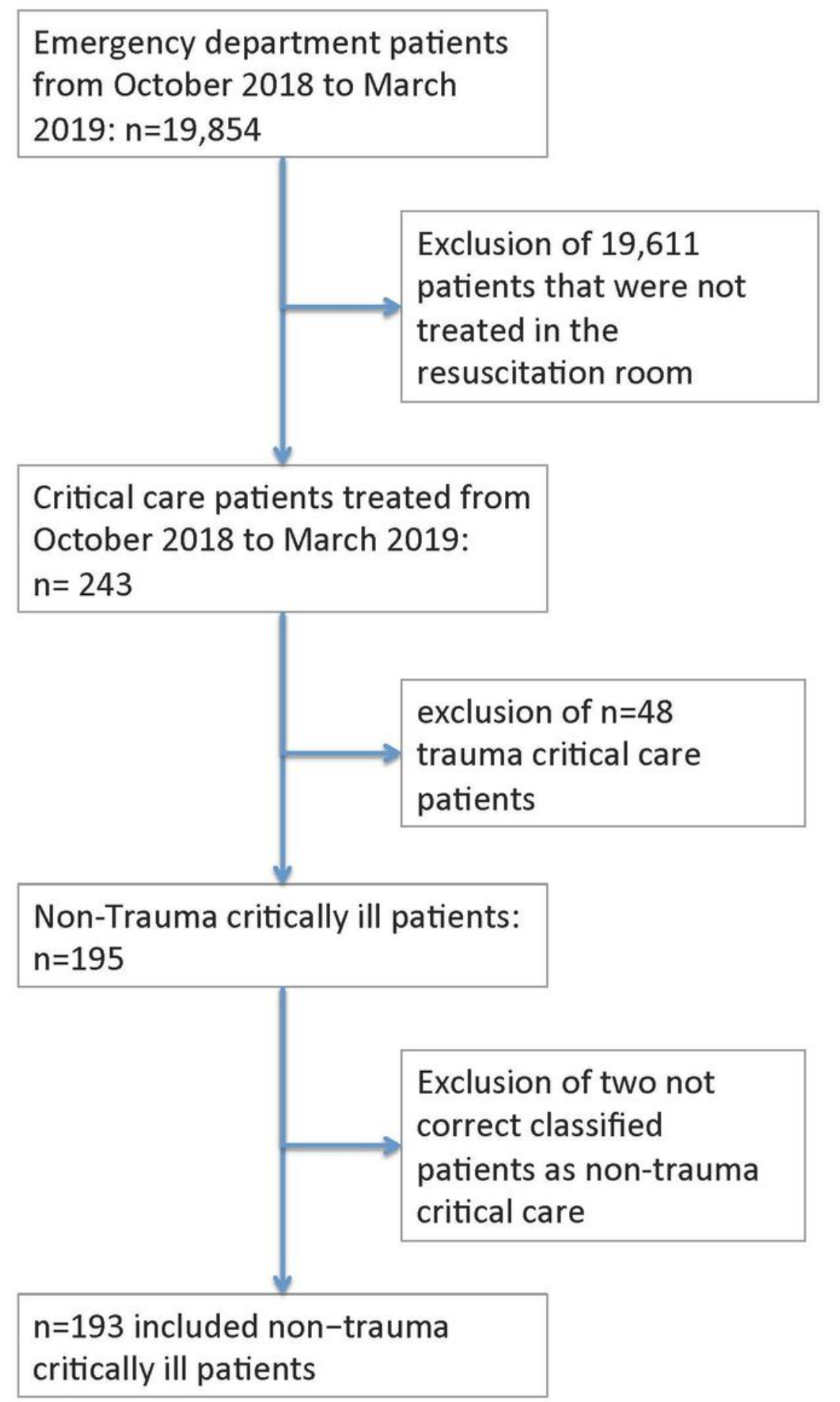

Figure 1

Study flow chart

\section{Supplementary Files}

This is a list of supplementary files associated with this preprint. Click to download. 
- LettertotheeditorBergrathetal.docx

Page 19/19 